\title{
ANTECEDENTES POBLACIONALES EN LOS INICIOS DEL MUNICIPIO CONSTITUCIONAL
}

\author{
por \\ Enrique Orduña Rebollo
}

A propósito de un Encuentro sobre Población y Territorio organizado por el IEAL, y del interés que para los antecedentes históricos de la cuestión pueda tener el documento que recientemente hemos adquirido para la Biblioteca del Instituto de Estudios de Administración Local, redactamos esta nota que realmente constituye una pequeña síntesis del problema histórico poblacional y territorial, así como un comentario del libro referenciado.

El concepto de población y territorio municipal que aparece en la vigente legislación de régimen local (1) tiene sus antecedentes articulados en el Reglamento sobre Población y Términos Municipales de 2 de julio de 1924, emanado de la normativa estatutaria de Calvo Sotelo que con algunas variaciones se repetiría en la legislación local del gobierno del General Franco. La inspiración democrática de la norma hoy en vigor, modifica el contenido y aleja aquellos antecedentes.

Pero esta cuestión del territorio y la población tienen una gran importancia e interés desde los mismos orígenes del Municipio constitucional por lo que vamos a tratar de investigar en aquellas raíces la veracidad de nuestro aserto. Tal importancia va a quedar marcada primero en algunas respuestas de la consulta al país realizada en 1810, después en los debates del texto doceañista y final-

(1) Reglamento de Población y Demarcación Territorial de las Entidades Lo cales, aprobado por Real Decreto 1690/1986, de 11 de julio (BOE núm. 194, de 14 de agosto de 1986). 
mente en las sucesivas disposiciones que fueron configurando la vida municipal española en los cortos períodos de libertades públicas comprendidas entre 1812 y 1833. En las respuestas dadas por las instituciones y personas a quienes se remitieron las preguntas que se conocen por «la consulta al país» en 1809 , hay múltiples interpretaciones dada la heterogeneidad de los consultados, pero casi todos coincidirán en la necesidad de implantar Ayuntamientos a partir de un determinado número de habitantes, que oscilará entre los quinientos y los mil ciudadanos, así como que dispongan de alcalde $o$ alcaldes pedáneos todos los pueblos.

Habrá una clara coincidencia de reformar el régimen municipal, de acabar con la venta de oficios, restaurando un sistema electivo indirecto, pero no habrá referencias a las reformas carolinas del reinado anterior. Igualmente hubo unanimidad en la abolición de los señoríos jurisdiccionales, figura de dificilísima evaluación por su gran variedad y número, pues a título de ejemplo, sólo la Audiencia de Galicia fijaba la pervivencia de 1.160 jurisdicciones en su territorio, de las cuales sólo eran 45 las de realengo (2).

En consecuencia, frente a la existencia de una jurisdicción plural de carácter señorial la Constitución de Cádiz va a tratar de resolverlo de manera uniforme extendiendo Ayuntamientos por todo el Reino con la consiguiente abolición de cualquier privilegio (3).

Para ello según el artículo 310 de la Constitución de 1812 se preveía la existencia de Ayuntamientos en los pueblos que no los hubiese y fuese conveniente su existencia, siendo obligatoria para los que por sí o por su "comarca lleguen a mil almas», cuestión ampliamente debatida y en la que tuvieron importante y decisiva participación los diputados americanos (4).

El concepto de población quedará desarrollado en la Instrucción para el gobierno político-económico de las Provincias de 23 de junio

(2) Vid. Artola, Miguel: Los orígenes de la España Contemporánea, 2.` ed., vol. II, Madrid, 1975, pág. 285. También GaRcfa FERNÁNDEZ, Javier: El origen del Municipio constitucional, IEAL, Madrid, 1983, págs. 214 y sigs. JiméNEZ DE GREGoRIo, Fernando: La convocatoria a Cortes Constituyentes en 1810. Estado de la opinión española en punto a la reforma constitucional, Madrid, 1955. SUÁREZ VeRDAGUER, Federico: El proceso de la convocatoria a Cortes (1808-1810), Pamplona, 1982. Tomás Y Valiente, Francisco: Manual de Historia del Derecho, Madrid, 1979.

(3) Vid. ORDUÑA ReBOllo, Enrique: «El cambio institucional», en Historia de Castilla y León. Liberalismo y Caciquismo, tomo IX, Valladolid, 1986, pág. 133.

(4) Vid. Garcta Fernandez, J.: El origen..., op. cit., págs. 256 y sigs. Cuestión también recogida por Concepción DE CASTRO: Los Diputados americanos..., y que igualmente se puede deducir de la lectura de las actas de las Cortes, correspondientes a tales asuntos. 
de 1813 que en su artículo 2..$^{\circ}$ preveía el envío por parte de los Ayuntamientos al Jefe Político de la Provincia cada tres meses «una nota de los nacidos, casados y muertos en el pueblo extendida por el cura párroco».

Pero el máximo desarrollo de los principios constitucionales de Cádiz en el ámbito del territorio y la población local lo vamos a encontrar en el capítulo II, artículo $1 .^{\circ}$, de la misma disposición, referente a «las Obligaciones y cargos de las Diputaciones Provinciales", ya que siendo competencia suya:

«El cuidado del establecimiento de Ayuntamientos en los pueblos donde no le haya" ... debería "tomar razón exacta del vecindario de cada pueblo donde haya de establecerse Ayuntamiento para que sí llegase por sí o con su comarca a las 1.000 almas se establezca desde luegon.

También preveía el referido artículo que en caso de no llegar a tal número de habitantes pero sí lo aconsejaban razones de interés público la conveniencia de establecerlo, debía instruirse un expediente en tal sentido, acompañando los informes previos de los pueblos comarcanos sobre la designación de términos o cualquier pueblo donde debía establecerse un nuevo Ayuntamiento. Todo el expediente, junto al instruido por la Diputación, en el que tenía que constar la opinión de la misma, debería ser remitido por el Jefe Político - no olvidemos su condición de presidente nato de la institución con voz y voto- al Gobierno de la Nación.

En definitiva, podemos detectar un escaso desarrollo de los preceptos constitucionales en materia de población y territorio pero no olvidemos que nos encontramos ante la primera norma que aborda el problema de la organización del nuevo régimen local constitucional y al margen de consideraciones diversas sobre su mayor o menor grado de autonomía, representatividad, etc., en general nos encontramos ante un temprano e inexperto intento de la andadura municipalista a partir de la Constitución de 1812, agobiado además, por el escaso margen de tiempo en que se desenvolverá el período constitucional incipiente, pues no olvidemos que casi un año después la reacción absolutista convertiría en papel mojado la obra del constitucionalismo doceañista.

Al retorno de las libertades públicas, cuando se produzca el trienio liberal, nuevamente el régimen local tendrá adversa fortuna, pues la norma que le regulará se promulgó el 3 de febrero de 1823, 
pocos meses antes de que se implantase un nuevo período absolutista que no acabaría, en esta ocasión, hasta 1833. Sin embargo la "Instrucción para el gobierno económico-político de las Provincias» de la referida fecha, estará en vigor intermitentemente a lo largo de otros períodos constitucionales posteriores hasta 1856 , con un total próximo a los diez años de vigencia en un espacio cronológico de treinta y tres.

En realidad nos encontramos con la primera Ley de Régimen Local del siglo xIx, ley que se puede calificar de radicalmente democrática y bastante descentralizadora. Aunque partía del pensamiento francés, razón que podía suponerla influida por criterios centralizadores, éstos quedaban suavizados y equilibrados por el mayor grado de intervención popular que existía en la vida municipal.

Quizá la visión más interesante por hacer un resumen del conjunto sea la opinión de PosadA para el cual la Instrucción de 1823 constituyó:

«Una verdadera Ley de Régimen Local, articulada y distribuida según la concepción que se iba formando de la organización de las representaciones locales; concepción más definida que la de 1813, pero siempre supeditada a la preocupación al servicio del Estado...» (5).

En el ámbito territorial el impacto va a ser mayor, primero en 1822 y definitivamente en 1833. Pues en tales fechas se va a dar cumplimiento al mandato del artículo 11 de la Constitución gaditana que advertía: "Se hará una división más conveniente del territorio español por una ley constitucional, luego que las circunstancias políticas de la Nación lo permitan".

Ciertamente el impacto de la división territorial del primer tercio del siglo XIX va a condicionar no sólo la estructura del Estado sino su modelo de organización territorial, pues como es sabido la última de las divisiones citadas se encuentra aún en vigor y es previsible su perduración tras el refrendo constitucional de 1978, que reconoce a la Provincia como Entidad local con personalidad jurídica propia.

La división provincial a que se refiere el artículo 11 de la Constitución de Cádiz no era novedoso en la historia de la organización territorial de España, así como tampoco su base física: la Provin-

(5) Vid. PosadA, Adolfo: Evolución legislativa del Régimen Local de España, 2.' ed., Madrid, 1982, pág. 122. 
cia (6); mas lo escueto de este trabajo nos impide profundizar en la cuestión, por lo que nos limitamos a describir el contenido y desarrollo de los intentos realizados para la articulación del territorio español en Provincias.

El primer intento liberal de reforma territorial, en cumplimiento del mandato constitucional, es el realizado por Felipe BAUZA a quien se lo había encargado la Regencia el 26 de junio de 1813. El proyecto hecho por BAUZÁ estaba basado en los mapas de Tomás LÓPEZ pero con criterios de "funcionalidad económica», proponiendo la existencia de 10 Provincias de primera, 18 de segunda y 16 de tercera, surgidas éstas de las de primera.

También cita Guaita que las Provincias fueron divididas en 1814 en Partidos (7), pero tanto en un caso como en otro, la llegada a España de Fernando VII y la derogación de la Constitución el 4 de mayo de 1814, supondría la vuelta de toda la actividad legislativa a la situación anterior a 1808 .

La ocasión para cumplir el artículo 11 de la Constitución de 1812 se va a presentar en el trienio liberal, cuando el Gobierno remita a las Cortes un proyecto de división y sea aprobado como Ley Cons. titucional, por Decreto de las Cortes de 27 de enero de 1822, y en el que significativamente figurará que la división realizada lo es con «calidad provisional». El Decreto no hace mención a las Regiones históricas citadas en el artículo 11 de la Constitución gaditana, porque las considera superadas al poner en marcha y desarrolla el referido artículo.

La relación de Provincias será de cincuenta y dos, algunas nuevas como Almería, Calatayud, Logroño, Badajoz, Vigo, Villafranca del Bierzo, Chinchilla y Játiva. Las otras serían las ya existentes en las anteriores divisiones, aunque de esas desaparecerían algunas como Toro, Astorga, Mérida, Ciudad Rodrigo y Jerez.

(6) El origen de la Provincia española se encuentra en las ciudades con voto en Cortes. De forma institucionalizada con fines económicos aparece en 1594 al aprobarse el Servicio de Millones y se mantendrá hasta nuestros dias tras las reformas del siglo xvill en las que ya adquiere carácter administrativo. Hoy nadie con rigor mantiene la tesis de la aparición de la Provincia como invento de Javier DI: BuRgos a imagen y semejanza del sistema francés, versión muy de moda en el pretérito régimen del general Franco. Véanse como base de nuestra afirmación los trabajos del profesor Miguel ARTOLA, principalmente: La Economia española al final del Antiguo Régimen. Instituciones, Madrid, 1982; Garricos Y PIco, Eduardo: "Organi7ación Territorial a fines del Antiguo Régimen», en La Economia..., págs. 1-10; Gualta, Aurelio: División Territorial y Descentralización, IEAL, Madrid, 1975, donde perfila las reformas y antecedentes del siglo XVIII, 1810, 1822 y 1833; ORIUÑa Rebollo, E.: «El cambio institucional...n, op. cit., págs. 137 y sigs.

(7) Vid. GinitA, Aurelio: División..., op. cit., paig. 2. 
Las posibilidades de reforma previstas en los artículos 13 a 15 según los cuales las Diputaciones Provinciales informarían al Gobierno de la conveniencia de efectuar modificaciones, fueron eliminadas por la vuelta al absolutismo, tras el Decreto de 1 de octubre de 1823.

Habrá que esperar otros diez años para iniciar una recuperación de las libertades y al tiempo entrar en el Estado constitucional definitivamente, rompiendo con la sociedad estamental, cuya presencia de iure se prolongará hasta 1836.

El 29 de septiembre de 1833 muere Fernando VII y dos meses más tarde el 30 de noviembre se promulga el Real Decreto mandando hacer la división territorial de Provincias más conocido por la división de Javier DE BURGos (8).

La división de 1833, articulaba la relación de Provincias en base a los antiguos Reinos, pero esta concepción regional es un artilugio ficticio que no pasa del papel: todos sabemos que a lo largo del siglos XIX y gran parte del Xx, ni los antiguos Reinos, ni las Regiones tienen absolutamente ningún papel administrativo o político. Sólo existen Provincias con un régimen común, presididas por los conceptos de legalismo uniformista, centralización y jerarquización. El régimen común se exceptuará con Vascongadas y Navarra, que mantendrán en lo económico y fiscal un status distinto en función de sus conciertos económicos. Como prevé el artículo $4 .^{\circ}$, la división no se limitó sólo al orden administrativo sino que se acomodaron a ella las «demarcaciones militares, judiciales y de Hacienda».

Como indicábamos anteriormente, en fecha reciente ha ingresado en la Biblioteca del Instituto de Estudios de Administración Local un documento impreso de singular importancia para el cono-

(8) Esta división que como hemos visto no tiene grandes diferencias respecto de la de 1822. fue realizada en un corto espacio de tiempo tras el nombramiento de Javier DE BuRGos, el cual dispuso de un equipo que elaboró unos estudios, los cuales fueron tomados como base para establecer los límites provinciales. Probablemente tales estudios estuviesen ya realizados cuando Javier DF: BuRGos se hace cargo del Ministerio de Fomento. Lo cierto es que no hubo improvisaciones como se deduce igualmente de las Instrucciones aprobadas por el Real Decreto de la Reina gobernadora del mismo día 30 de noviembre, en el que da las normas de gobierno de los subdelegados de Fomento, pues en el capítulo XVIII, referido a la "división territorial y estadistica", inicia su artículo 62 con estas palabras: "A pesar del esmero, de la atención y del tiempo que se ha empleado en la nueva división territorial...." Lamentablemente no hemos tenido acceso a los estudios previos, pese a nuestra minuciosa búsqueda en los Archivos: Histórico Nacional, Alcalá, Interior y Consejo de Estado. 
cimiento de la población y de la organización territorial española en 1834. Se trata de la Subdivisión en Partidos Judiciales de la nueva División Territorial de la Peninsula e Islas adyacentes, aprobada por S. M. en el Real Decreto de 21 de abril de 1834, Madrid. En la Imprenta Real. 1834.

El libro contiene el texto del mencionado Decreto que ya nos era conocido, y además el modo y la forma, de acuerdo con el artículo $1^{\circ}$, en que se subdividía España en Partidos Judiciales, que en la Colección de Decretos de la Reina (9) no aparecía, explicando en nota a pie de página, las razones de tal omisión pues «no se inserta por no sobrecargar este tomo y porque se vende por separado". Y este documento que se vendía por separado, es el que ha llegado a nuestras manos y que hoy comentamos.

El Decreto más conocido tiene gran interés por tratarse en realidad de la consolidación de la obra territorial de Javier DE Burgos, pese a que ésta no había pasado por las Cortes y constaba que era también provisional como la división realizada en 1822. Pero pese a que en el siglo XIx hay intentos de modificar la división de 1833, sin que naturalmente ninguno prosperase, pensamos que tal provisionalidad podía ser una mera declaración formal de intenciones, sin constituir un firme y decidido propósito el hacerlo, como han demostrado los hechos, perdurando hasta hoy lo realizado entonces, y en tal sentido lo confirma el artículo $2 .^{\circ}$ del Decreto de 21 de abril de 1834, cuando dice: «Esta división se entiende aprobada sin perjuicio de las alteraciones que la experiencia acredite ser necesarias para su mayor perfección".

Cierto que se refiere a Partidos Judiciales que en el futuro sufrirán modificaciones, pero cierto también que su base es la Provincia y sobre ella se realizan las subdivisiones como reza el mismo título del Decreto.

Creemos que la división territorial de España en Provincias, hecha por Javier DE BURGos en 1833, y la que nos ocupa en Partidos Judiciales, realizada cinco meses más tarde, eran firmes aunque no cerraban la puerta a una posible reforma o modificación. Por ejemplo, en el caso de las Provincias, la división de las Canarias ya en nuestro siglo y en el caso de los Partidos Judiciales, las modifica-

(9) Lo que posteriormente se conocerá como Colección Legislativa de España, a partir de los años sesenta del pasado siglo. En este momento se denominará exactamente: Decretos de la Reina Nuestra Señora Doña Isabel II. Madre de Reina gobernadora (enero, 1834-1836) por Josef Nieva, Madrid, Imprenta Real. 
ciones y sobre todo las recientes supresiones y agrupaciones de cabeceras motivadas por la inmigración y la concentración de población en los núcleos urbanos que había dejado sin sentido la existencia de algunos Partidos Judiciales. En nuestros días la posibilidad de reforma en el territorio de las Provincias, también está previsto por la Constitución cuando en el artículo 141, refiriéndose a ellas, dice: «Cualquier alteración de los límites provinciales habrá de ser aprobada por las Cortes Generales mediante ley orgánica».

Otra cuestión especificada en el Real Decreto de 21 de abril es el cese de los Alcaldes ordinarios en sus funciones judiciales, las cuales debían ser traspasadas inmediatamente a los Jueces de los Partidos nombrados específicamente para tales fines. Estamos ante la consumación legal de la separación de poderes, con que se estaba iniciando la balbuceante andadura del Estado liberal liquidando reminiscencias del Antiguo Régimen.

Singular interés ha tenido para nosotros, como decíamos anteriormente, la incorporación del libro a los fondos documentales del IEAL, pues el mencionado apéndice constituye la primera relación de pueblos después de la Constitución de 1812, realmente desconocida hasta ahora, pues si bien es lógico pensar que el libro tuvo una cierta difusión en los años próximos a su edición y que habrá sido obra habitual en los Juzgados, y dependencias de la Administración de Justicia, su rareza y escasez se manifestó pronto ya que incluso PaLAU, en su Manual del Librero Hispanoamericano, da sólo dos valoraciones del documento, una en 1930 y otra en 1960 , ya de por sí elevadas para la época.

La obra hay que inscribirla por su importancia en la categoría de la «España dividida en Provincias e Intendencias y Subdividida en Partidos, Corregimientos, Alcaldías Mayores, Gobierno Políticos y Miiltares. Así Realengos como de Ordenes, Abadengo y Señorío"... realizado por Floridablanca en 1785 y publicado en dos tomos en 1789. Ciertamente es un nomenclátor de carácter nacional en el que sólo se nota la ausencia de las cuatro Provincias forales: Alava. Guipúzcoa, Vizcaya y Navarra.

El texto se presenta por orden alfabético de Provincias, dentro de cada una de éstas figuran los Partidos Judiciales y todos sus pueblos, también alfabetizados. Al referirse a éstos, hace mención de caseríos o parroquias cuando existen. Al final de cada Provincia figura un resumen en el que constan los Partidos Judiciales, especificando el total de pueblos, vecinos y almas. 
La suma de todas las Provincias, excluidas las forales, nos da para 1834 un total de 451 Partidos Judiciales, 15.369 pueblos y 2.993 parroquias. Datos muy interesantes, pues hasta la publicación del Diccionario Geográfico-Estadístico-Histórico, de D. Pascual MADOZ (1845-1850), no se realizará un nuevo intento de nomenclátor municipal. Por ello debemos sacar la conclusión de que la elevada suma de pueblos y parroquias que alcanza un total de 18.394, queda bastante lejos del número real de Municipios que debían existir en aquel momento.

A este respecto debemos indicar la ausencia de una cifra rigurosa y fiable sobre la existencia de Ayuntamientos a partir de 1812, pues hay que tener en cuenta que en los períodos liberales se van constituyendo donde no los había, a la vez van desapareciendo las jurisdicciones especiales, los señoríos son abolidos, etc., por lo que lógicamente existe un número indeterminado de pueblos en los que se crean Ayuntamientos. Por esta dificultad y por el elevado número de pueblos y parroquias, la información que facilita este libro no puede tomarse como riguroso censo de Ayuntamientos existentes, sino más como un nomenclátor de pueblos.

De cualquier forma parece imposible que cinco meses escasos después de la muerte de Fernando VII, y en una época transicional, de democracia tutelada, como diríamos hoy, el número de Ayuntamientos constituidos fuese tan elevado, el punto de comparación más próximo es el ya mencionado Diccionario Geográfico de Pascual MADOZ, el cual si bien es un verdadero monumento e impresionante banco de datos municipal para su tiempo, también es un hecho constatado que se encuentran múltiples errores e inexactitudes y su fiabilidad en cuanto a asuntos concretos no es muy grande. Entre ellos el número de Municipios. Creemos que para un cómputo más riguroso habrá que recurrir al censo de 1857 para determinar más exactamente los aspectos poblacionales del Municipio español.

Como apéndice a nuestro trabajo hemos incorporado dos Anexos, uno el número de Partidos Judiciales, Pueblos y Parroquias existentes por Provincias y el otro un análisis comparativo de las Provincias de Valladolid y Avila, tomadas como muestra, en los dos repertorios a que estamos haciendo referencia: el Decreto de Partidos Judiciales y el Diccionario Geográfico de MADOZ, complementado con el Censo de 1887 y finalmente el Censo de 1981.

El estudio del primer aspecto nos muestra que además del elevado número de parroquias de Asturias y las Provincias gallegas, 
otras Provincias con numerosos pueblos como Burgos o León, suponen que hoy tienen el mayor número de Entidades Locales Menores de toda España.

Burgos: 669 ELM (10) (1.214 pueblos R. D. 1834).

León: 1.255 ELM (1.351 pueblos R. D. 1834).

Palencia: 224 ELM (456 pueblos R. D. 1834).

Santander: 534 ELM (643 pueblos R. D. 1834).

alcanzando prácticamente el 90 por 100 del total.

A partir del Decreto de 1834, comparando con los datos de Madoz, Censo de 1887 y Censo de 1981, para las Provincias de Avila y Valladolid, observamos una disminución creciente, pero no muy ostensible entre el número de pueblos en 1834 y de Municipios en 1845-50, 1887 y 1981.

Las diferencias para Avila son:

$\begin{array}{lll}-99 & -20 & -3\end{array}$

En el caso de Avila las diferencias son más apreciables entre el número de Ayuntamientos de Madoz y el de pueblos del R. D. 1834, lo que no ocurre en Valladolid. No debe inducirnos a error esta proximidad, y considerar el R. D. de 1834 como un Censo de Municipios, sino sólo como un Nomenclátor como hemos indicado anteriormente; máxime teniendo en cuenta las razones alegadas de dificultad en la constitución de Ayuntamientos que hemos mencionado.

Habrá que realizar en un futuro próximo nuevas investigaciones que nos aclaren algo más la cuestión y se pueda establecer con rigor la existencia de la organización municipal en la primera mitad del siglo XIX.

(10) Censo de Entidades Locales Menores, SNIACL, Madrid, 1976 (31-12-1975). 


\section{ANEXO I}

\begin{tabular}{|c|c|c|c|}
\hline Provincia & $\begin{array}{c}\text { Número de } \\
\text { Partidos } \\
\text { Judiciales }\end{array}$ & Pueblos & Parroquias \\
\hline $\begin{array}{lllllllll}\text { Albacete } & \ldots & \ldots & \ldots & \ldots & \ldots & \ldots & \ldots & \ldots\end{array}$ & 8 & 118 & \\
\hline $\begin{array}{lllllllll}\text { Alicante } & \ldots & \ldots & \ldots & \ldots & \ldots & \ldots & \ldots & \ldots\end{array}$ & 16 & 206 & \\
\hline $\begin{array}{llllllllll}\text { Almería } & \ldots & \ldots & \ldots & \ldots & \ldots & \ldots & \ldots & \ldots & \ldots\end{array}$ & 9 & 114 & \\
\hline $\begin{array}{llllllllll}\text { Asturias } & \ldots & \ldots & \ldots & \ldots & \ldots & \ldots & \ldots & \ldots & \ldots\end{array}$ & 15 & & 815 \\
\hline $\begin{array}{llllllllll}\text { Avila } & \ldots & \ldots & \ldots & \ldots & \ldots & \ldots & \ldots & \ldots & \ldots\end{array}$ & 6 & 389 & \\
\hline $\begin{array}{lllllllll}\text { Badajoz } & \ldots & \ldots & \ldots & \ldots & \ldots & \ldots & \ldots & \ldots\end{array}$ & 14 & 170 & \\
\hline $\begin{array}{llllllll}\text { Barcelona } & \ldots & \ldots & \ldots & \ldots & \ldots & \ldots & \ldots\end{array}$ & 11 & 543 & \\
\hline $\begin{array}{lllllllll}\text { Baleares } & \ldots & \ldots & \ldots & \ldots & \ldots & \ldots & \ldots & \ldots\end{array}$ & 6 & 108 & \\
\hline $\begin{array}{lllllllll}\text { Burgos } & \ldots & \ldots & \ldots & \ldots & \ldots & \ldots & \ldots & \ldots\end{array}$ & 12 & 1.214 & \\
\hline $\begin{array}{lllllllll}\text { Cáceres } & \ldots & \ldots & \ldots & \ldots & \ldots & \ldots & \ldots & \ldots\end{array}$ & 13 & 240 & \\
\hline $\begin{array}{lllllllll}\text { Cádiz } & \ldots & \ldots & \ldots & \ldots & \ldots & \ldots & \ldots & \ldots\end{array}$ & 12 & 45 & \\
\hline $\begin{array}{lllllllll}\text { Canarias } & \ldots & \ldots & \ldots & \ldots & \ldots & \ldots & \ldots & \ldots\end{array}$ & 11 & 121 & \\
\hline $\begin{array}{lllllllll}\text { Castellón } & \ldots & \ldots & \ldots & \ldots & \ldots & \ldots & \ldots & \ldots\end{array}$ & 10 & 154 & \\
\hline 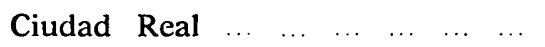 & 9 & 121 & \\
\hline $\begin{array}{lllllllll}\text { Córdoba } & \ldots & \ldots & \ldots & \ldots & \ldots & \ldots & \ldots & \ldots\end{array}$ & 15 & 110 & \\
\hline $\begin{array}{llllllll}\text { Coruña, } \mathbf{L a} & \ldots & \ldots & \ldots & \ldots & \ldots & \ldots & \ldots\end{array}$ & 14 & & 925 \\
\hline $\begin{array}{lllllllll}\text { Cuenca } & \ldots & \ldots & \ldots & \ldots & \ldots & \ldots & \ldots & \ldots\end{array}$ & 9 & 333 & \\
\hline $\begin{array}{lllllllll}\text { Gerona } & \ldots & \ldots & \ldots & \ldots & \ldots & \ldots & \ldots & \ldots\end{array}$ & 6 & 562 & \\
\hline $\begin{array}{lllllllll}\text { Granada } & \ldots & \ldots & \ldots & \ldots & \ldots & \ldots & \ldots & \ldots\end{array}$ & 13 & 244 & \\
\hline $\begin{array}{llllllll}\text { Guadalajara } & \ldots & \ldots & \ldots & \ldots & \ldots & \ldots & \ldots\end{array}$ & 9 & 397 & \\
\hline $\begin{array}{lllllllll}\text { Huelva } & \ldots & \ldots & \ldots & \ldots & \ldots & \ldots & \ldots & \ldots\end{array}$ & 6 & 90 & \\
\hline $\begin{array}{lllllllll}\text { Huesca } & \ldots & \ldots & \ldots & \ldots & \ldots & \ldots & \ldots & \ldots\end{array}$ & 7 & 736 & \\
\hline $\begin{array}{llllllllll}\text { Jaén } & \ldots & \ldots & \ldots & \ldots & \ldots & \ldots & \ldots & \ldots & \ldots\end{array}$ & 11 & 111 & \\
\hline $\begin{array}{llllllllll}\text { León } & \ldots & \ldots & \ldots & \ldots & \ldots & \ldots & \ldots & \ldots & \ldots\end{array}$ & 10 & 1.351 & \\
\hline $\begin{array}{lllllllll}\text { Lérida } & \ldots & \ldots & \ldots & \ldots & \ldots & \ldots & \ldots & \ldots\end{array}$ & 8 & 910 & \\
\hline $\begin{array}{lllllllll}\text { Logroño } & \ldots & \ldots & \ldots & \ldots & \ldots & \ldots & \ldots & \ldots\end{array}$ & 9 & 285 & \\
\hline $\begin{array}{llllllllll}\text { Lugo } & \ldots & \ldots & \ldots & \ldots & \ldots & \ldots & \ldots & \ldots & \ldots\end{array}$ & 11 & & 1.258 \\
\hline $\begin{array}{lllllllll}\text { Madrid } & \ldots & \ldots & \ldots & \ldots & \ldots & \ldots & \ldots & \ldots\end{array}$ & 7 & 223 & \\
\hline $\begin{array}{lllllllll}\text { Málaga } & \ldots & \ldots & \ldots & \ldots & \ldots & \ldots & \ldots & \ldots\end{array}$ & 13 & 113 & \\
\hline $\begin{array}{llllllllll}\text { Murcia } & \ldots & \ldots & \ldots & \ldots & \ldots & \ldots & \ldots & \ldots & \ldots\end{array}$ & 8 & 76 & \\
\hline $\begin{array}{lllllllll}\text { Orense } & \ldots & \ldots & \ldots & \ldots & \ldots & \ldots & \ldots & \ldots\end{array}$ & 11 & 858 & \\
\hline $\begin{array}{lllllllll}\text { Palencia } & \ldots & \ldots & \ldots & \ldots & \ldots & \ldots & \ldots & \ldots\end{array}$ & 7 & 456 & \\
\hline $\begin{array}{llllllll}\text { Pontevedra } & \ldots & \ldots & \ldots & \ldots & \ldots & \ldots & \ldots\end{array}$ & 11 & 658 & \\
\hline $\begin{array}{llllllll}\text { Salamanca } & \ldots & \ldots & \ldots & \ldots & \ldots & \ldots & \ldots\end{array}$ & 8 & 527 & \\
\hline $\begin{array}{llllllll}\text { Santander } & \ldots & \ldots & \ldots & \ldots & \ldots & \ldots & \ldots\end{array}$ & 12 & 643 & \\
\hline $\begin{array}{lllllllll}\text { Segovia } & \ldots & \ldots & \ldots & \ldots & \ldots & \ldots & \ldots & \ldots\end{array}$ & 5 & 339 & \\
\hline $\begin{array}{lllllllll}\text { Sevilla } & \ldots & \ldots & \ldots & \ldots & \ldots & \ldots & \ldots & \ldots\end{array}$ & 12 & 127 & \\
\hline $\begin{array}{lllllllll}\text { Soria } & \ldots & \ldots & \ldots & \ldots & \ldots & \ldots & \ldots & \ldots\end{array}$ & 5 & 540 & \\
\hline $\begin{array}{llllllll}\text { Tarragona } & \ldots & \ldots & \ldots & \ldots & \ldots & \ldots & \ldots\end{array}$ & 7 & 290 & \\
\hline
\end{tabular}




\begin{tabular}{|c|c|c|c|}
\hline Provincia & $\begin{array}{c}\text { Número de } \\
\text { Partidos } \\
\text { Judiciales }\end{array}$ & Pueblos & Parroquias \\
\hline $\begin{array}{llllllllll}\text { Teruel } & \ldots & \ldots & \ldots & \ldots & \ldots & \ldots & \ldots & \ldots & \ldots\end{array}$ & 10 & 293 & \\
\hline $\begin{array}{lllllllll}\text { Toledo } & \ldots & \ldots & \ldots & \ldots & \ldots & \ldots & \ldots & \ldots\end{array}$ & 12 & 222 & \\
\hline $\begin{array}{llllllll}\text { Valladolid } & \ldots & \ldots & \ldots & \ldots & \ldots & \ldots & \ldots\end{array}$ & 9 & 274 & \\
\hline $\begin{array}{lllllllll}\text { Valencia } & \ldots & \ldots & \ldots & \ldots & \ldots & \ldots & \ldots & \ldots\end{array}$ & 15 & 245 & \\
\hline $\begin{array}{lllllllll}\text { Zamora } & \ldots & \ldots & \ldots & \ldots & \ldots & \ldots & \ldots & \ldots\end{array}$ & 7 & 485 & \\
\hline $\begin{array}{lllllllll}\text { Zaragoza } & \ldots & \ldots & \ldots & \ldots & \ldots & \ldots & \ldots & \ldots\end{array}$ & 12 & 354 & \\
\hline $\begin{array}{lllllll}\text { TOTAL } & \ldots & \ldots & \ldots & \ldots & \ldots & \ldots\end{array}$ & 451 & 15.396 & 2.998 \\
\hline
\end{tabular}

PROVINCIA DE AVILA

\begin{tabular}{|c|c|c|c|c|}
\hline Partido Judicial & $\begin{array}{l}\text { Número } \\
\text { pueblos } \\
R D 1834\end{array}$ & $\begin{array}{c}\text { Número } \\
\text { Aytos. } \\
\text { Madoz }\end{array}$ & $\begin{array}{c}\text { Censo } \\
1887\end{array}$ & $\begin{array}{c}\text { Censo } \\
1981\end{array}$ \\
\hline Arenas de San Pedro ... & 22 & 21 & 19 & \\
\hline $\begin{array}{lllllll}\text { Arévalo } & \ldots & \ldots & \ldots & \ldots & \ldots & \ldots\end{array}$ & 71 & 68 & 59 & \\
\hline $\begin{array}{lllllll}\text { Avila } & \ldots & \ldots & \ldots & \ldots & \ldots & \ldots\end{array}$ & 107 & 87 & 77 & \\
\hline Barco de Avila $\ldots \ldots$... & 75 & 29 & 30 & \\
\hline $\begin{array}{llllll}\text { Cebreros } & \ldots & \ldots & \ldots & \ldots & \ldots\end{array}$ & 32 & 20 & 20 & \\
\hline $\begin{array}{lllllll}\text { Piedrahita } & \ldots & \ldots & \ldots & \ldots & \ldots\end{array}$ & 82 & 65 & 65 & \\
\hline $\begin{array}{lllll}\text { TOTAL } & \ldots & \ldots & \ldots & \ldots\end{array}$ & 389 & 290 & 270 & 267 \\
\hline
\end{tabular}


PROVINCIA DE VALLADOLID

\begin{tabular}{|c|c|c|c|c|}
\hline Partido Judicial & $\begin{array}{c}\text { Número } \\
\text { pueblos } \\
R D 1834\end{array}$ & $\begin{array}{c}\text { Número } \\
\text { Aytos. } \\
\text { Madoz }\end{array}$ & $\begin{array}{c}\text { Censo } \\
1887\end{array}$ & $\begin{array}{c}\text { Censo } \\
1981\end{array}$ \\
\hline Medina del Campo ... ... & 27 & 26 & 21 & \\
\hline Mota del Marqués ... .. & 39 & 40 & 24 & \\
\hline Navara del Rey $\ldots \ldots \ldots$ & 10 & 11 & 9 & \\
\hline $\begin{array}{llllll}\text { Olmedo } & \ldots & \ldots & \ldots & \ldots & \ldots\end{array}$ & 39 & 38 & 34 & \\
\hline $\begin{array}{llllll}\text { Peñafiel } & \ldots & \ldots & \ldots & \ldots & \ldots\end{array}$ & 36 & 33 & 30 & \\
\hline $\begin{array}{llllll}\boldsymbol{R} \text { Rioseco } & \ldots & \ldots & \ldots & \ldots & \ldots\end{array}$ & 30 & 24 & 23 & \\
\hline Valoria la Buena ... .. & 30 & 28 & 26 & \\
\hline $\begin{array}{llllll}\text { Valladolid } & \ldots & \ldots & \ldots & \ldots & \end{array}$ & 22 & 21 & 17 & \\
\hline $\begin{array}{llllll}\text { Villalón } & \ldots & \ldots & \ldots & \ldots & \ldots\end{array}$ & 41 & 40 & 37 & \\
\hline $\begin{array}{lllll}\text { Tordesillas } & \ldots & \ldots & \ldots & \ldots\end{array}$ & & & 16 & \\
\hline $\begin{array}{lllll}\text { TOTAL } & \ldots & \ldots & \ldots & . .\end{array}$ & 274 & 261 & 237 & 232 \\
\hline
\end{tabular}


REALA-1987, núm. 233. ORDUÑA REBOLLO, ENRIQUE. ANTECEDENTES POBLACIONALES EN LOS... 
REVISTA

$\mathrm{DE}$

ESTUDIOS

DE LA

ADMINISTRACION

LOCAL

Y AUTONOMICA

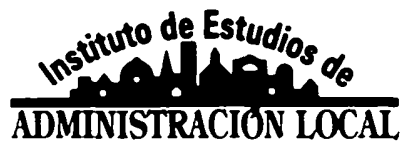

II. CRONICAS 
REALA-1987, núm. 233. ORDUÑA REBOLLO, ENRIQUE. ANTECEDENTES POBLACIONALES EN LOS...

REALA-1987, núm. 233. ORDUÑA REBOLLO, ENRIQUE. ANTECEDENTES POBLACIONALES EN LOS... 